\title{
Corrigendum
}

\section{The relationship between coping and subclinical psychotic experiences in adolescents from the general population - a longitudinal study - Corrigendum}

\author{
A. Lin, J. T. W. Wigman, B. Nelson, W. A. M. Vollebergh, J. van Os, G. Baksheev, J. Ryan, \\ Q. A. W. Raaijmakers, A. Thompson, A. R. Yung
}

doi:10.1017/S0033291711000560. Published online by Cambridge University Press, 28 April 2011.

In our recent published study (Lin et al. 2011), an error was made in reporting the number of participants. The overall number of participants involved in the study at each stage was: T1 (baseline), $n=881$; T2 (12 months after baseline), $n=652$; T3 (3 years after baseline assessment), $n=512$.

The number of participants with Community Assessment of Psychic Experiences (CAPE) data at any assessment was $n=875$. These are the participants included in latent class analysis, as originally reported.

The authors apologise for this error.

\section{Reference}

Lin A, Wigman JTW, Nelson B, Vollebergh WAM, van Os J, Baksheev G, Ryan J, Raaijmakers QAW, Thompson A, Yung AR (2011). The relationship between coping and subclinical psychotic experiences in adolescents from the general population-a longitudinal study. Psychological Medicine. doi:10.1017/ S0033291711000560. 